importance of that factor-of recognizing that the new universities are communities of men and women with pride and ambition in their subjects and in their institutions-is implicit in the PEP report and also in that from the Inter-University Council. Both reports present a great challenge, not only to all directly concerned in the enterprises which they survey but also to the body of informed opinion in Britain which already appreciates how much is at stake, and how simple are some of the measures required to avoid waste of effort and frustration. Confidence and co-operation must take the place of distrust and suspicion towards Britain that endanger the political, economic and social development of the Colonial territories, and the ultimate evolution of self-governing States within the Commonwealth, which are the declared aims of British Colonial policy. An important step to meet that challenge is offered by the material collected in "The Colonial Territories, 1954-55" and elsewhere for the creation of an informed public opinion, alive to the responsibilities of Britain in those territories and sensitive to the needs of those peoples, whether they remain in their own territories, or seek to fit themselves in Britain to serve their countrymen.

\section{LOW-TEMPERATURE PHYSICS}

\section{Progress in Low Temperature Physics}

Edited by Prof. C. J. Gorter. (Series in Physics.) Pp. xii +418. (Amsterdam : North-Holland Publishing Company, 1955.) 30.50 guilders; 61s.; 8 dollars.

DURING the past ten years or so, the commercial availability of the Collins cryostat has enabled many new laboratories, particularly in the United States, but also in France, India, Japan and elsewhere, to work at liquid-helium temperatures, previously a monopoly of only a few specialized laboratories ; and there has been, in consequence, an enormous expansion of activity in low-temperature physics. The appearance of this collection of review articles-about half from laboratories which have only recently entered the field-is therefore to be welcomed. Such review articles enable the research worker specializing in any one branch of lowtemperature physics to keep up with progress in others without having to read all the original literature; because many of the principles and techniques are common to all branches, this may well give him new ideas for his own special problem as well as broadening his outlook.

The best method of presenting a review article depends very much on the nature and scope of the subject. For a rather limited topic, it is possible to give a critical survey of the experimental and theoretical situation, using tables and illustrative graphs with full references to the literature, in quite a short space. An admirable example of this style of treatment is E. F. Hammel's article on liquid helium3 , which guides the reader through a very tangled situation and shows just what has been achieved. A less-successful example is C. F. Squire's article on the effect of stress on superconductivity-an even more limited topic, but not sufficiently systematically presented and lacking an adequate theoretical dis- cussion. At the other extreme there is the much wider topic, such as the technique of adiabatic demagnetization and its many applications, which demands a much larger space if coverage in full detail is to be achieved. This approach has been adopted by D. de Klerk and M. J. Steenland, whose article on adiabatic demagnetization is the longest in the book ( 62 pages) and almost a monograph in its own right ; it can be read with profit by anyone who wishes to learn the subject in detail from the beginning, but is perhaps unnecessarily detailed for the low-temperature physicist to whom the book is primarily addressed. Alternatively, this kind of topic can be treated in more general terms with no attempt at a complete build-up but with a selection of illustrative examples; this is A. H. Cooke's approach in his interesting 20-page review on paramagnetic crystals in use at low temperatures. Probably the ideal lies between the two, assuming rather more specialized theoretical knowledge than de Klerk and Steenland but giving a rather more detailed development than Cooke.

Nearly all the articles are reviews of already published work; but R. P. Feynman's article on the application of quantum mechanies to the liquidhelium problem deserves special mention as being not so much a review as an original contribution, in which he presents important new developments of his recent ideas, in a form assimilable by the experimental physicist. These new ideas stress the importance of turbulence in the flow of liquid helium and are particularly suggestive for new experiments.

The eighteen articles cover a wide variety of subjects ; about half are concerned with the properties of liquid helium and superconductors, and the remainder deal with paramagnetism, antiferromagnetism, ferromagnetism, propagation of sound, and transport properties of gases. There is some overlapping (between B. Serin's article on superconducting critical fields and J. G. Daunt's on elec tronic specific heats of metals, which might well have been combined) and the choice of detailed topics seems a little haphazard. It is, however, explained in the editorial preface that this choice has been governed partly by expediency (where the competent authority was not available to deal with a particular topic at the time) and partly by the existence of recent review articles on some topics which it seemed unnecessary to treat again for a while.

On the whole, the articles are successful in achieving their object, and it is to be hoped that the valuable service rendered by this collection of articles will be continued in at least a second volume. Perhaps, however, in such a second volume the editor might aim at rather greater uniformity in the scope and level of treatment of the articles.

\section{SHOENBERG}

\section{FRUIT PRODUCTION}

\section{The Fruit Year Book, 1955}

(No. 8.) Edited by P. M. Synge and Lanning Roper. Pp. $142+30$ plates. (London: Royal Horticultural Society, 1954.) 10s. ; 1.65 dollars.

A LTHOUGH the cultivation of fruit trees in the A specialized sense began early in the past century, so much new knowledge of its problems and potentialities comes with each year that a year-book is necessary to record the progress. The complexities of the situation are well portrayed in the present 